\title{
Case Report \\ Uretero-Iliac Artery Fistula: A Diagnostic and Therapeutic Challenge
}

\author{
Muhammad Z. Aslam, ${ }^{1,2}$ Ferhad Kheradmund, ${ }^{1}$ Nilay Patel, ${ }^{1}$ and David Cranston ${ }^{1}$ \\ ${ }^{1}$ Department of Urology, Oxford Radcliffe Hospitals, Oxford OX3 7LJ, UK \\ ${ }^{2}$ Friarage Hospital, Hambleton Wing, Northallerton, DL6 1JG, UK \\ Correspondence should be addressed to Muhammad Z. Aslam, mzaslam77@yahoo.com
}

Received 9 January 2010; Accepted 18 February 2010

Academic Editor: Darius J. Bagli

Copyright (C) 2010 Muhammad Z. Aslam et al. This is an open access article distributed under the Creative Commons Attribution License, which permits unrestricted use, distribution, and reproduction in any medium, provided the original work is properly cited.

Uretero-Iliac artery fistulas (UAFs) are very uncommon in urological practice. The rarity of this clinical entity may lead to a delayed or missed diagnosis which can result in life-threatening consequences. We present a case of a right ureteric and right external iliac artery fistula, its presentation, diagnosis, and management along with the review of the literature.

\section{Case Report}

A 54-year-old lady underwent Total Abdominal Hysterectomy and Bilateral Salpingo-Oophorectomy followed by pelvic radiotherapy for carcinoma of the cervix. She presented 3 years later with a history of recurrent frank hematuria and haemodynamic instability. Her haemoglobin on admission was $6.9 \mathrm{~g} / \mathrm{dl}$. A cystoscopy demonstrated areas of radiotherapy changes only. A CT scan demonstrated blood clots within the right collecting system.

Progressive right-sided hydronephrosis was noted along with progressive deterioration in renal function. A nephrostomy and subsequent antegrade stenting were performed on the right side. Over the next few weeks, the patient went on to have periodic stent changing to improve the renal functions and massive blood transfusions performed to stabilize the dropping haemoglobin.

During a subsequent attempt to replace the right ureteric stent, the bladder filled with bright red blood clot as soon as the stent was removed. A retrograde ureteropyelogram was performed, which directly and inferolaterally demonstrated contrast flow in the line of the external iliac artery suggesting a ureteroarterial fistula. A Digital Subtraction Angiographic run confirmed a hemodynamically significant uretero-external iliac arterial fistula (Figure 1). Vascular access was promptly secured and a flush aortogram followed by superselective runs identified a false aneurysm of the right common iliac artery (Figure 2). A covered $12 \mathrm{~mm} \times$ $60 \mathrm{~mm}$ FLUENCY plus vascular stent graft (C. R. Bard, Inc.) was placed in the right common and external iliac artery (Figure 3). Followup arteriography showed the false aneurysm not to be filling. A retrograde study performed 4 days later had shown no leakage. A further followup 8 weeks later had shown the patient to be completely asymptomatic.

\section{Discussion}

Uretero-iliac artery fistula (UAF) is a rare but potentially lifethreatening condition [1]. The usual presenting symptom varies from intractable microscopic haematuria to gross hematuria occurring intermittently for a number of days. A variety of medical conditions and activities can predispose to the formation of UAF which include vascular factors such as degenerative vascular diseases and previous vascular surgery. Other non vascular factors include pelvic radiation and chemotherapy, pelvic surgery, previous urinary diversion, and ureteral stenting [2].

Though the exact mechanism of the development of UAF is still uncertain, it has been postulated that as a result of previous radiation therapy and pelvic or vascular surgical procedures, the integrity of vasa vasorum could be disrupted. This results in a weakening of the adventitia and media of the large arteries and increasing their susceptibility to rupture 


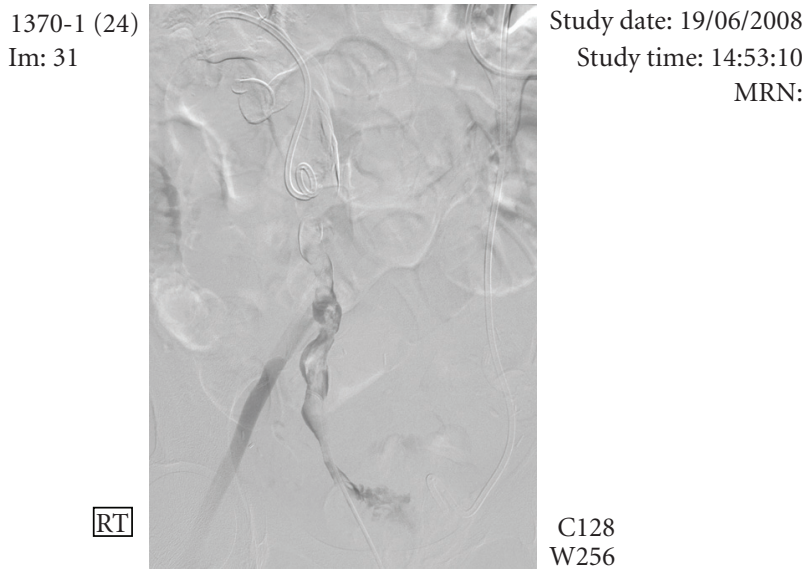

Figure 1: Uretero-external iliac artery fistula demonstrated on angiographic run.

and necrosis. The ureter can become fixed and obstructed by the surrounding inflammatory process. Chronic pulsations to the fibrosed, less compliant ureter can cause necrosis and eventually formation of a fistula [3]. Fistula formation could further be hastened by having a fixed ureteral stent in place [1].

Clinical awareness of the possibility of this condition is the most important of all diagnostic steps. Patients who underwent an exploratory laparatomy without any adequate preoperative diagnosis were reported to have a mortality rate of $64 \%$ and a retreatment rate of $25 \%$ [2]. Whereas, a mortality rate of $0 \%$ was described in patients in whom the diagnosis was considered before an elective operation was performed [4].

Some authors have supported the diagnostic role of Magnetic Resonance Angiography [5] and CT scan [6] for diagnosis while most go in favour of retrograde ureteropyelography $[5,7]$. Ureteroscopy under high pressure gradient has also been reported to confirm the site of hematuria, with a diagnostic accuracy of $64 \%$ [3].

Angiography particularly provocative angiography remains the most important diagnostic tool [8]. Provocative angiography involves manipulation of a ureteral stent during investigation to provoke active and detectable bleeding of the fistula. Such a provocative angiogram has been advised to be performed with appropriate surgical backup to handle severe hemorrhage [1].

Treatment of a diagnosed or suspected UAF requires a multidisciplinary approach involving urologists, radiologists and vascular surgeons. Open surgery remains the first line treatment $[5,6]$. This involves ligation of the involved artery, with or without bypass revascularization, as well as direct suturing with a patch graft in combination with urinary diversion, nephrostomy, or nephrectomy [2]. At least 2 cases in the literature $[9,10]$ were treated by autotransplantation of the kidney which helped to make a new anastomosis of the ureter possible, since a large part of the ureter had sustained damage as a result of the fistula. Other options include iliac artery embolization with bypass [1] and transrenal ureteral occlusion with Gianturco coils [11].

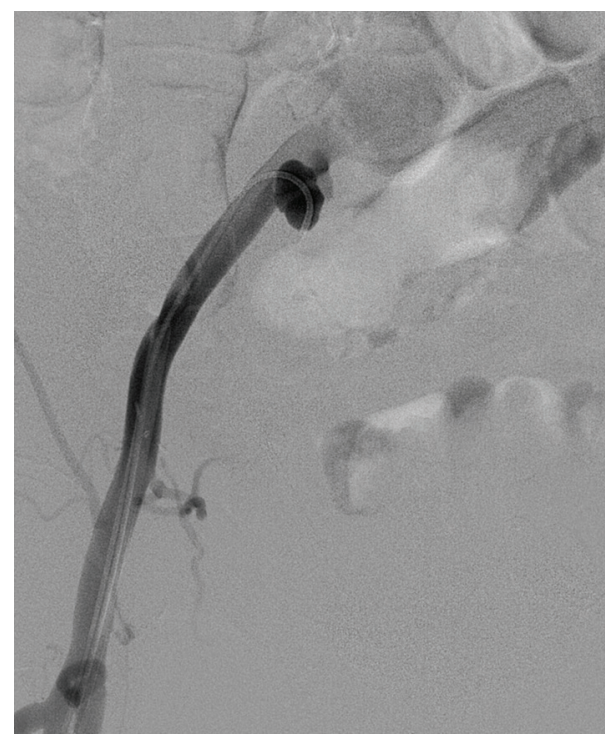

Figure 2: False aneurysm of the right common iliac artery demonstrated.

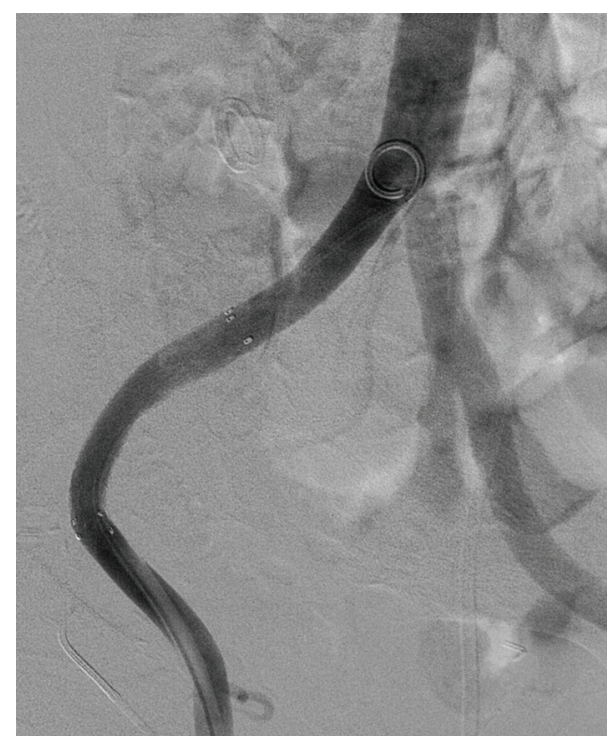

FIGURE 3: A covered stent securely placed in the right common and external iliac artery.

During the past few years endovascular techniques have proven not only to be effective but also very rapid in this emergency condition. A major advantage of the arterial stent is that it does not compromise the vascular supply and there is no need for additional bypass operations [9]. Despite the fact that stents carry with them the risk of infection, they are the best possible treatment options in unstable patients in emergency situations and in patients who are not fit for surgery.

\section{Conclusion}

UAF remains a rare and a life-threatening emergency. A high index of suspicion should be maintained by the 
dealing physicians in patients with a history of intermittent hematuria who have the previously mentioned predisposing factors and in whom other common causes of hematuria have been ruled out. A multidisciplinary approach is the best in achieving successful results.

\section{References}

[1] S. J. Batter, F. J. McGovern, and R. P. Cambria, "Ureteroarterial fistula: case report and review of the literature," Urology, vol. 48, no. 3, pp. 481-489, 1996.

[2] S. P. Quillin, M. D. Darcy, and D. Picus, "Angiographic evaluation and therapy of ureteroarterial fistulas," American Journal of Roentgenology, vol. 162, no. 4, pp. 873-878, 1994.

[3] G. F. Abercrombie and W. F. Hendry, "Ureteric obstruction due to peri-aneurysmal fibrosis," British Journal of Urology, vol. 43, no. 2, pp. 170-173, 1971.

[4] D. Bergqvist, H. Pärsson, and A. Sherif, "Arterio-ureteral fistula- a systematic review," European Journal of Vascular and Endovascular Surgery, vol. 22, no. 3, pp. 191-196, 2001.

[5] Y. Matsui, K. Fujikawa, H. Oka, S. Fukuzawa, and H. Takeuchi, "Ureteroarterial fistula in a patient with a single functioning kidney," International Journal of Urology, vol. 8, no. 3, pp. 128129, 2001.

[6] N. Muraoka, T. Sakai, H. Kimura, et al., "Endovascular treatment for an iliac artery-ureteral fistula with a covered stent," Journal of Vascular and Interventional Radiology, vol. 17, no. 10, pp. 1681-1685, 2006.

[7] P. Hilderbrand, et al., "Uretero-iliac artery fistula. A rare cause of massive haematuria," Scandinavian Journal of Urology and Nephrology, vol. 38, pp. 434-435, 2004.

[8] D. R. Vandersteen, R. R. Saxon, E. Fuchs, F. S. Keller, L. M. Taylor Jr., and J. M. Barry, "Diagnosis and management of ureteroiliac artery fistula: value of provocative arteriography followed by common iliac artery embolization and extraanatomic arterial bypass grafting," Journal of Urology, vol. 158, no. 3, pp. 754-758, 1997.

[9] R. C. van den Bergh, F. L. Moll, J. P. de Vries, K. K. Yeung, and T. M. Lock, "Arterio-ureteral fistula: 11 new cases of a wolf in sheep's clothing," The Journal of Urology, vol. 179, no. 2, pp. 578-581, 2008.

[10] A. Bullock, G. L. Andriole, N. Neuman, and G. Sicard, "Renal autotransplantation in the management of a ureteroarterial fistula: a case report and review of the literature," Journal of Vascular Surgery, vol. 15, no. 2, pp. 436-441, 1992.

[11] T. Inoue, T. Hioki, Y. Arai, Y. Inaba, and Y. Sugimura, "Ureteroarterial fistula controlled by intraluminal ureteral occlusion," International Journal of Urology, vol. 9, no. 2, pp. 120-121, 2002. 


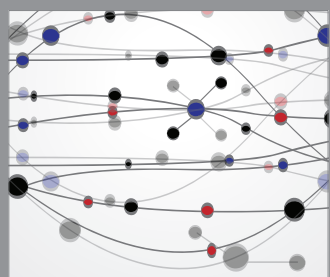

The Scientific World Journal
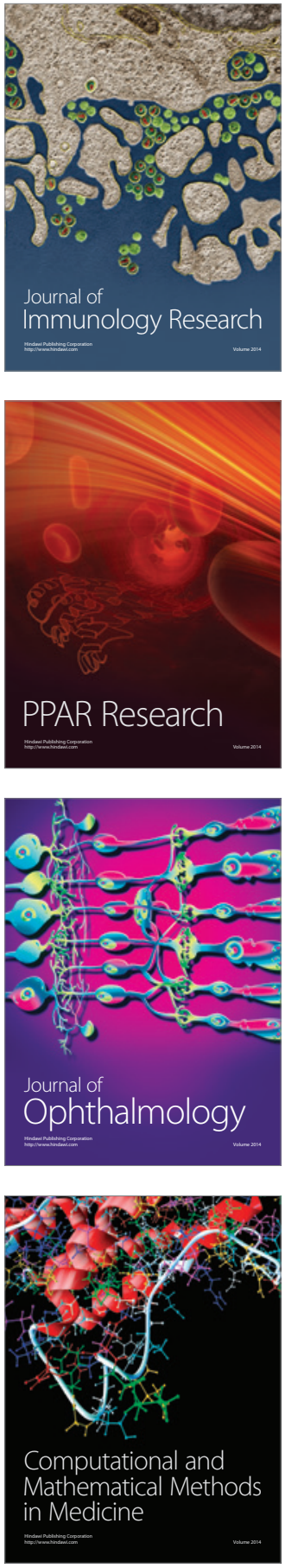

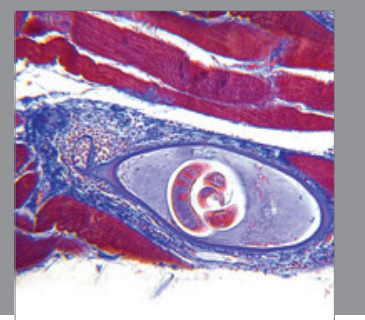

Gastroenterology

Research and Practice
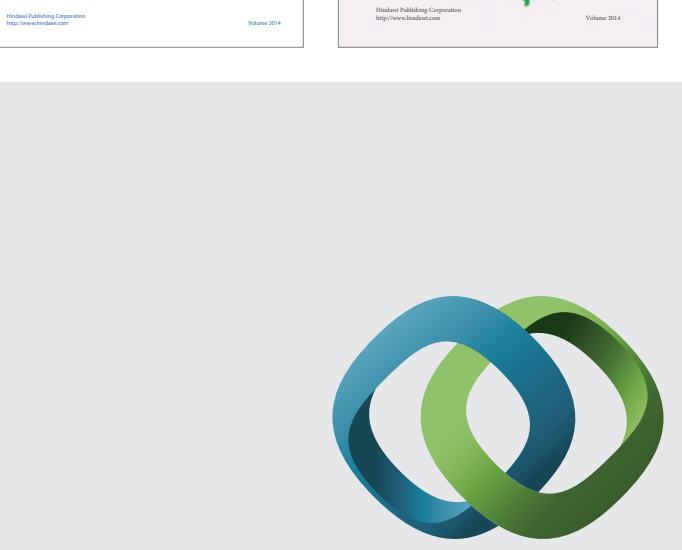

\section{Hindawi}

Submit your manuscripts at

http://www.hindawi.com
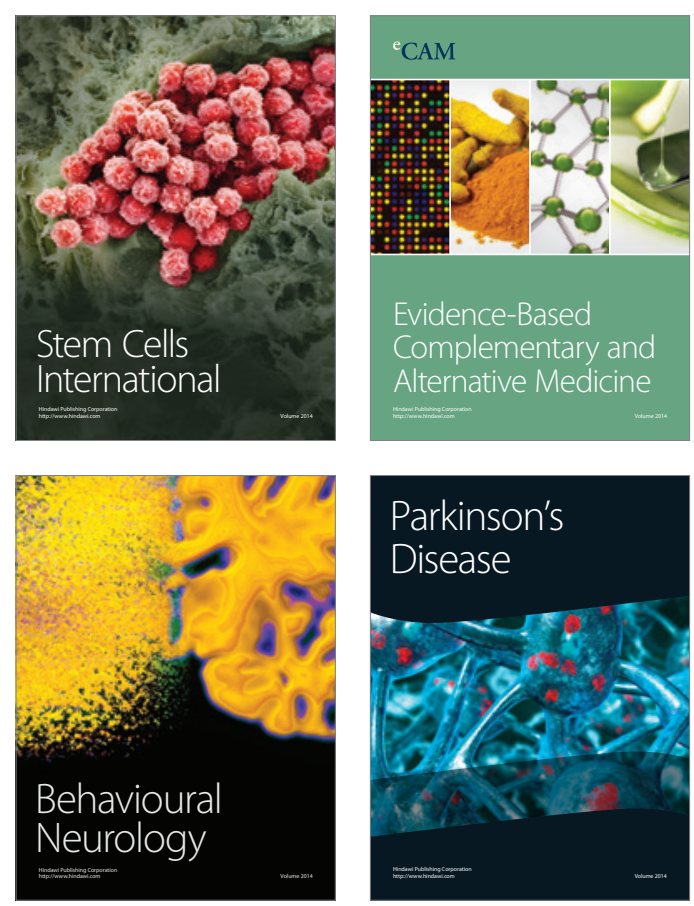

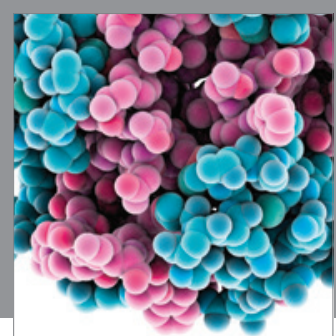

Journal of
Diabetes Research

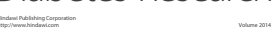

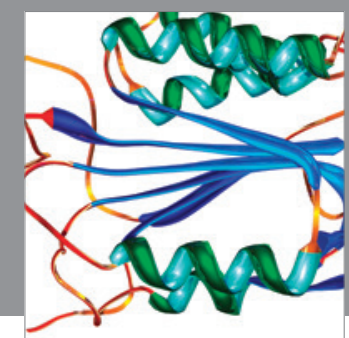

Disease Markers
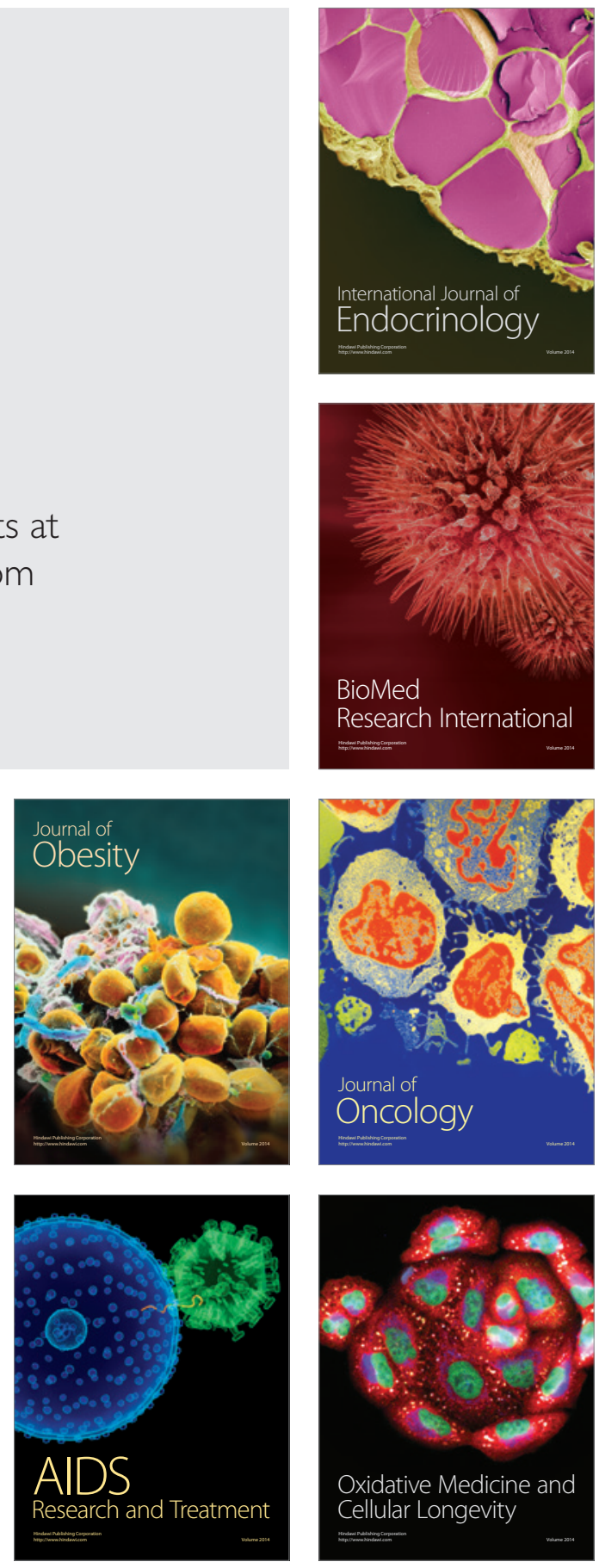